\title{
RECOGIMIENTOS FEMENINOS EN LA NUEVA ESPAÑA Y SU PAPEL COMO CÁRCELES PARA MUJERES MARGINADAS ${ }^{1}$
}

\author{
Robin AnN Rice \\ Universidad Popular Autónoma del Estado de Puebla - México \\ robinann.rice@upaep.mx
}

$\mathrm{U}$

na sociedad se articula por medio de sus esquemas moralizantes y punitivos. Los casos de mujeres en recogimientos virreinales mexicanos son un crisol que tal vez nos podría iluminar la vida cotidiana y sus prácticas ambiguas hacia la mujer en cuanto a estos esquemas. Desde sus inicios, los recogimientos de mujeres en la Nueva España son un síntoma de la relación problemática de ellas con la sociedad. Las mujeres eran una fuente de ansiedad en la sociedad novohispana: fueran religiosas o laicas, tenían que seguir estrictas reglas sobre usos y costumbres femeninos, a veces escurridizos (Hernández-Torres 2018-2019; Uribe 2016; Castillo Hernández 2014).

Los recogimientos eran baluartes multifuncionales. En ciertas épocas se destinaron únicamente al entrenamiento religioso místico, pero también impartieron clases de lectura, costura, bordado, cocina y otras destrezas mujeriles a niñas (Howe 2008). Al mismo tiempo, funcionaron bajo otros criterios. Este estudio examina tres casos de mujeres aprisionadas en los recogimientos de Santa María Magdalena tanto de la Puebla de los Ángeles como de la Ciudad de México. El nombre de estos recogimientos es indicativo de una de sus principales funciones. La santa simbolizaba a la mujer pecadora, pero arrepentida y reformada. Por

$1 \quad$ Este artículo se ha desarrollado dentro del proyecto «La mujer frente a la Inquisición española y novohispana» (FEM2016-78192-P), I+D de Excelencia del Ministerio de Economía y Competitividad (MINECO), financiado por la Agencia Estatal de Investigación (AEI) y el Fondo Europeo de Desarrollo Regional (FEDER, UE); y del grupo de investigación «Mentalidades mágicas y discursos antisupersticiosos (siglos XVI, XVII y XVIII)», grupo consolidado por la Universidad Autónoma de Madrid.

Edad de Oro, XXXVIII (2019), pp. 235-248, ISSN: 0212-0429 - ISSNe: 2605-3314

DOI http://doi.org/10.15366/edadoro2019.38.012 
ejemplo, las prostitutas o alegradoras penitentes podrían encontrar un lugar de refugio y protección para expiar sus malos actos. También, dado que no era aceptable que las mujeres vivieran solas, los recogimientos sirvieron para alojar a las solteras, casadas con problemas matrimoniales, divorciadas y viudas. Alojaron esposas de soldados o comisionados que se vieron en la necesidad de viajar a otras partes del mundo para cumplir con órdenes de las autoridades. Y por fin, hubo los que albergaban a las mujeres acusadas de mala conducta.

Habría que entender el término «delincuente» muy ampliamente, porque muchas de las mujeres encerradas forzosamente en estos recintos, si bien cometieron actos que incomodaron a las autoridades, no delinquieron en el sentido moderno de la palabra. Como afirmó Josefina Muriel, el pensamiento jurista del XVIII va creando un nuevo léxico: la palabra «delincuente» reemplazaría el término «pecadora», y las transgresiones serían contra la sociedad en lugar de contra Dios (1974: 116); pero esta distinción era muy borrosa en cuanto a las mujeres sancionadas. El propósito de este escrito es examinar los casos de tres mujeres: Mariana de la Cruz, Gregoria Piedra «la Macho» y Juana Rodríguez «la Paya». Mariana de la Cruz y Juana Rodríguez fueron sentenciadas al recogimiento de Santa María Magdalena en la Puebla de los Ángeles, que cambió su nombre a Santa María Egipciaca. Por su parte, Gregoria Piedra fue clausurada en Santa María Magdalena de la Ciudad de México. También se examinarán las supuestas transgresiones que suscitaron la condena de estas mujeres al olvido en los recogimientos. Por la desdibujada distinción entre «delito» $\mathrm{y}$ «pecado» en la modernidad temprana atlántica y por el estado social tan vulnerable en que vivían muchas mujeres, perdieron su libertad y bienestar físicos de un día para otro.

\section{Tipos De tribunales}

La mala conducta de los individuos era juzgada en los tribunales establecidos en la Nueva España: «el Tribunal de la Real Audiencia, con sus salas Civil y Criminal; el Tribunal de la Inquisición, para las faltas contra la fe y las costumbres»; seguía el «Tribunal de la Acordada que perseguía a los bandoleros» (Muriel 1974: 38). En los primeros tiempos, la Real Cárcel fue el destino para los condenados por la Real Audiencia; y en las cárceles preventivas, secretas y perpetuas acabaron los que fueron juzgados por el tribunal de la Inquisición. Josefina Muriel afirma que la mayoría de los crímenes contra la fe se castigaban públicamente, por ejemplo: «ir a misa con mordaza y vela en la mano; pasear por las calles con un sambenito; ir sobre un jumento por las plazas públicas con insignias vergonzantes; [...] recibir azotes en un Auto de fe», etc. (Muriel 1974: 38). Durante los juicios contra la fe, la Inquisición perseguía delitos contra brujas, curanderas y 
hechiceras. En cuanto a crímenes contra las costumbres, «la Inquisición castigaba a las [mujeres] bígamas, a las amancebadas y a las adúlteras» (Muriel 1974: 39); y en el siglo XVII, muchos de estos castigos se llevaron a cabo en recogimientos. Sin embargo, en el siglo XVIII «la mayoría de las mujeres delincuentes eran remitidas por todos los diferentes tribunales que existían en Nueva España [los del Real Audiencia y la Inquisición] a cumplir sus sentencias en los recogimientos» (Muriel 1974: 39). Las condenas interminables en los casos examinados son a causa de esta confusión entre la justicia secular del Estado y la eclesiástica. A veces, los expedientes se intercambiaban entre los distintos brazos jurídicos sin poder desenredar el número de años de condena ni la severidad del quebrantamiento social.

El arzobispo Lanciego y Eguílaz avisó al Rey en la segunda década del siglo XVII que las mujeres perdidas del Hospital de la Misericordia podrían ser atendidas en otro lado y que quería cambiar el giro de aquel lugar para mejor recoger «mujeres casadas discordes con sus maridos». Quería salvaguardar la familia y su estrategia incluía amparar a las mujeres o más bien «castigarla[s] para que corrigie$\mathrm{ra}[\mathrm{n}]$ su conducta». A fin de cuentas, una vida de «austeridad conventual» les daría el tiempo para reflexionar «sobre sus faltas para con el marido y los hijos, y darles la oportunidad de perdonar o ser perdonadas» (Muriel 1974: 58). Las mujeres pedían el divorcio más frecuentemente que los hombres por motivos de «malos tratos, amenazas de muerte, golpes, insultos públicos y privados, adulterio» (Muriel 1974: 64), además de las causas normales relacionadas con falta de apoyo económico y cierta proclividad a los vicios. Castigadas más frecuentemente por pequeñas faltas que los hombres, las mujeres eran demandadas por «adulterio, negación a hacer con ellos vida maridable, o abandono en sus deberes del hogar» (Muriel 1974: 64). Las infracciones más nimias se castigaban con frecuencia especialmente entre los grupos de mujeres de color. Sin embargo, lo que funcionaba en el siglo XVII, ya se había deteriorado por las últimas décadas del XVIII: «El trabajo como ocupación honesta y remunerada que se efectuó en las primeras décadas [en los recogimientos], fue siendo sustituido por un cruel trabajo forzado sin compensación alguna» (Muriel 1974: 155). Había llegado a tal extremo el maltrato en los recogimientos que, en las diligencias, quedó claro que la vida en la cárcel pública era más deseable que en aquellos, porque en la cárcel «el trabajo era remunerado y voluntario en tanto que en el recogimiento estaban obligadas a "hilar diariamente cuatro onzas de algodón" so pena de azotes» (Muriel 1974: 155).

Casarse o hacerse monja requería de una dote y podría conllevar otro tipo de problemas. El ejemplo famoso del convento como verdadero recogimiento es el de sor Juana Inés de la Cruz, quien pudo entrar en la Orden de Santa Paula o los jerónimos gracias a un generoso benefactor que pagó su dote. No obstante, fue asediada por todos lados: si los fastidios no provinieron de su confesor, se originaron por las tareas fastidiosas del convento o por las censuras del arzobispo y la 
santa Inquisición. Existía en otras latitudes la tercera vía, una vida religiosa femenina comunitaria sin la jurisdicción masculina. A partir del siglo XII, las beguinas causaron un escándalo porque prescindieron de la autoridad eclesiástica para fundarse y proliferarse en casas. En la Nueva España, sucedió algo semejante con los «beaterios», casas donde mujeres laicas, que tuvieran una inclinación religiosa, vivían en grupos y practicaban su propio estilo de religiosidad. En general, les culparon de relajación moral, en muchos casos, sin fundamento. Otro ejemplo de esta conducta «libertina» que no pedía la intervención de los jerarcas eclesiásticos fueron las mujeres que hacían fiestas religiosas espontáneas en sus casas. Personas privadas frecuentemente tenían altares en sus casas y organizaban ahí fiestas «religiosas» que se conocieron como «oratorios». Estos jolgorios comenzaron como celebraciones pías, pero poco a poco fueron subiendo de tono.

\section{Mariana de la Cruz}

(Biblioteca Palafoxiana, ms. [Papeles Varios], fF. 266r-272R, BP: R475)

Muchas veces, mujeres devotas organizaban oratorios o fiestas para celebrar algún santo importante en su comunidad. Un ejemplo es el caso de Mariana de la Cruz, mulata libre, que fue recluida en Santa María Magdalena en la Puebla de los Ángeles por haber organizado una de estas celebraciones en su casa, en mayo de 1649. En este caso, la mujer organizó un novenario para conmemorar el día de la Santa Cruz. Los mulatos y mestizos tenían una predilección por esta festividad que se ha celebrado desde el siglo Iv y es conmemorada el 3 de mayo. Su castigo fue devastador: dictaminaron prender «el cuerpo» de Mariana y «la ponga presa en el recogimiento de Santa María Magdalena» de la Puebla de los Ángeles y la encargaron a la «madre tutora» de tal recogimiento. También, confiscaron y embargaron todos sus bienes, que fueron abonados al tribunal eclesiástico o al recogimiento.

Una nota sobre el recogimiento de Santa María Magdalena, fundado entre 1580 y 1603 para «señoras nobles y prostitutas arrepentidas», hasta mediados del siglo XVII, el recogimiento fue semejante al de las monjas penitentes, puesto que llegaban por voluntad propia y con un interés sobrenatural. Con el tiempo, arribaban mujeres condenadas a un recogimiento forzado por tribunales eclesiásticos y civiles (Muriel 1974: 154). Como es natural, las religiosas que podían pagar la dote acudieron a conventos que no tenían esta doble función de recogimientos y cárceles. Se podría declarar lo mismo sobre señoras nobles, tal vez viudas, o las que se depositaron ahí en «resguardo» por sus maridos.

En total, ocho hombres testificaron en contra de Mariana, también implicando a otros en el supuesto «jolgorio»: siete mulatos libres y un español. Solo uno 
de los testigos, el español, supo firmar su nombre. Los sucesos que no variaron de testigo en testigo y son descritos palabra por palabra casi idénticamente son los que se relatan a continuación. Con el supuesto permiso del «señor obispo provisor», en el oratorio de la casa de Mariana, los testigos observaron un altar que tenía por frontal una sobrecama. Todo estaba muy bien aderezado, con muchas velas de sebo, una cantidad copiosa de flores y ramilletes, y una insignia de la Santa Cruz. La reunión estuvo amenizada por música durante toda la celebración. Incluso, todos coincidieron en que los participantes cantaban y bailaban durante el evento con mucho «escándalo y alboroto». En la calle, hubo fuegos, cohetes y luminarias. Por el elevado costo de ofrecer una fiesta con tantas galas y entretenimiento, se repartió, entre los entusiastas en la fiesta, el sufragio de los otros días del novenario. Para exculpar a Mariana o a sí mismos de la imputación, todos remarcaron que habían oído a alguien decir que el «señor obispo provisor» habría dado licencia para hacer la fiesta. Por esto, habían disfrutado del convivio sin preocupaciones. El único que habría sentido una supuesta «incertidumbre» por asistir fue el español, tal vez un testigo manipulable por ser compatriota de los jueces que, con verdadera consternación o no, reaccionó de esta manera, según su declaración: «Y maravillándose este testigo de cómo, contraviniendo a edictos del Santo Oficio y del señor obispo provisor, se tenía aquel novenario, y preguntando si tenía licencia, dijo Nicolás de Ribera, mulato músico que vive en el solar de don Juan Tello, como había licencia del señor provisor pues confiaba en esto, asistió y se divirtió».

Los mulatos libres y el español que testificaron en el caso implicaron a otras personas en la fiesta, incluso, nombrando los que se encargarían del subsidio de las celebraciones de los otros días del novenario. Según los testigos, las siguientes personas fueron acusadas de participar y, algunos son, también, los que patrocinarían los otros días de las fiestas. Los acriminados por los ocho testigos de asistir y asentir a apadrinar un día del novenario son: Teresa de Canales, negra esclava de Canales, el cirujano; Nicolás del Puerto, esclavo de Diego de Coca; Vicente Montejo, mulato libre que vive en Analco; Teresa, negra esclava de Juan de Vargas; Ana, mulata esclava de Diego Pérez, notario del Santo Oficio; María, mulata esclava de Diego Pérez, notario del Santo Oficio; Miguel, indio, candelero que vive en San Pablo; una mestiza llamada Ana. Pese a su condición humilde, un testigo apunta a que había cierto concurso entre los voluntarios patrocinadores a intentar superarse en elementos festivos en los días sucesivos. Además, si tomamos en cuenta que los costos del primer día corrieron por cuenta de Mariana misma, los otros ocho días habrían de ser financiados por cinco mujeres y tres hombres. La mayoría son esclavos. La advocación a la Santa Cruz fue grande si se toma en cuenta el gasto enorme que significaba el patrocinio de estas fiestas por esclavas y por personas de oficios humildes. 
Pareciera que estas ostentaciones de la fe serían positivas - que la evangelización rendía sus frutos entre los indígenas, pero también entre otras etnias-, pero el caso fue otro. Por «un intento de motín y otros actos de sedición por parte de negros y mulatos esclavos, [...] había muchos negros presos en la cárcel de México y se habían descubierto "grandes maldades y aún, a las vueltas, muchas negras y negros hechicheros"» (Mauléon 2018: 22). Para evitar que Puebla tuviera los mismos problemas, en 1612, se pregonó que los negros y mulatos, libres o esclavos, no podían llevar armas o formarse en grupos para cantar, hacer cofradías, bailar o ir más de tres a la vez. Específicamente, para la «fiesta de la Cruz» habría capitanes y oficiales alistando a sus subordinados para cuidar el orden en este día y en las procesiones de Semana Santa (Mauleón 2018: 22-23). Lo sorprendente es que la prohibición comprendía «actos públicos y privados que incluían danzas, bailes y juegos» (Mauleón 2018: 21). Un aliciente sustancial para estimular estas detenciones fue el pago de un peso de oro por «cada negro o mulato aprehendido» (Mauleón 2018: 21). Seguramente, después de la condena de Mariana, perseguirían a los negros y mulatos que habían sido testigos o asistentes al oratorio y así conseguirían su peso de oro.

La parte más notable y grave de este caso es la completa devastación material y social de Mariana de la Cruz. La esclava libre tenía una casa amplia porque contaba con una pieza únicamente para su oratorio y altar. Además, su situación económica le permitió costear el primer día de la fiesta con todos los lujos que se detallaron anteriormente. Con la condena, Mariana perdió todos sus bienes. Los casos son los únicos registros que se tienen de personas como Mariana y, después de su condena y sus subsiguientes desgracias, no se ha encontrado archivo alguno que la vuelva a mencionar.

\section{Gregoria Piedra «La Macho»}

(AGN, INQ., 1.349, EXP. 28, FF. 336-344)

Gregoria Piedra, alias «la Macho», tenía un pasado problemático pero el 21 de marzo de 1796, precisamente el Lunes Santo, su suerte se le acabó. En cuatro ocasiones había estado presa en la cárcel de la ciudad por vestirse como hombre, por pleitos y constantes participaciones en trifulcas. También, en el pasado, la habían atrapado en la iglesia del Sagrario por recomulgadora: tras comulgar vestida de hombre, había regresado para recibir el sacramento en ropa de mujer. La acusaron de tener intenciones de vender las cédulas en la calle. Anteriormente, durante tres meses, estuvo presa en la más lúgubre prisión de la Ciudad de México, la Acordada. Ahí, encerraban a bandidos, salteadores y criminales de todo tipo, miles de los cuales, terminaron en el patíbulo. Como indicativo de su estado precario, se 
sabe que había estado un tiempo en el hospicio de pobres. Nació en la Plazuela de las Vizcaínas en la Ciudad de México permaneciendo por aquella zona, pero cambiando frecuentemente de casa. Nunca hay mención de familiares.

«La Macho» era una mulata, prieta, hombruna en ademanes, con cara, cuerpo y manera de andar propio de los hombres. Tenía el pelo ondulado y en sus brazos y otras partes del cuerpo llevaba tatuajes con pinturas, símbolos y signos. En trajes de hombre, pero también, a veces, de mujer, normalmente se relacionaba más con las féminas por tener cierta «inclinación» hacia ellas. Ella aseguró que, por algún tiempo, había sido soldado en el regimiento de los pardos y, a veces, decía que había estado en el de caballería. Jugaba en la calle a la pelota, picado —un juego parecido a los dardos-y rayuela.

Gregoria alternaba su vestuario entre ropa de hombre y de mujer, pero la mayoría de las veces, se la recuerda vestida de hombre. Representa el caso de una mujer que, por un lado, importaba tan poco al sistema, que ninguna corte de justicia — ni la eclesiástica ni la secular - sabía el porqué de su castigo. Todo empezó el Lunes Santo, el 21 de marzo de 1796, cuando una mujer nombrada María Vicenta Vargas, habitante de una pajería, que no sabía contar, leer, firmar su nombre y juró no tener conocimiento de su edad, reportó que había observado que «cerca de ella, comulgó [...] en traje de hombre, una mujer nombrada Gregoria, y que inmediatamente que recibió la Sagrada Forma», tapó su cara con una mano y «con disimulo [...] la sacó de la boca [...] [con] sus sacrílegos dedos». La denunciante «se la encaró en acción de admiración y sorpresa, y al instante, se levantó la dicha Gregoria». Después, «la Macho» se volteó e hizo una seña con la mano a un muchacho, descrito como mediano, descalzo, pelón, de calzoncillo de cuero, que se levantó y salieron corriendo de la iglesia, riéndose. Cuando se habían huido del recinto, la mujer quitó de su cabeza una tela ancha — pintada en imitación a las de la China- que había usado como mantilla pese a su ropa de hombre.

Por esta acusación, días después, un sargento del regimiento del comercio, Joseph de Acosta, la capturó y la entregó a Juan Francisco de Anda, gobernador de la Real Sala del Crimen, quien la mandó a la Real Cárcel de Corte y, a la vez, pidió que se le informase al santo tribunal de la Inquisición, al cual consideró correspondía el conocimiento de este delito, por ser sospechosa en la fe. La detención se realizó el Viernes Santo, 25 de marzo de 1796, cuando la observaron en traje de hombre acompañando a los otros mirones, viendo pasar la procesión de aquel día. Se burló de ella e intentó soplar la vela de una participante para apagarla, mientras se reía con el muchacho de la iglesia.

Unos días después de su aprehensión, los inquisidores Mier y Bergosa pidieron al prefecto de cárceles un reporte secreto sobre el pasado de la mujer. En diciembre de 1796, el presbítero Agustín Montejano, capellán de la Real Casa de Santa María Magdalena, recogimiento en la Ciudad de México, recibió la entrega 
de la Cárcel de la Corte, una mujer de nombre Gregoria Piedra, alias «la Macho», condenada a ocho años de detención. Extrañamente, en 1797, el mismo capellán Montejano escribe a los inquisidores Mier, Bergoza y Prado que la encarcelada había pasado dos meses otra vez en la Cárcel de la Corte porque había armado un escándalo en el recogimiento por estar separada de las demás mujeres. Ahora, la habían regresado a Santa María Magdalena y el presbítero reportó que uno de los jueces le había dicho que Gregoria venía «a disposición del Santo Tribunal». Para no cometer un error en el Libro de entradas, suplicó saber si era correcto este dato, pues no quería "ocasionar algún trastorno en este asunto».

Los inquisidores no contestaron hasta enero de 1798 sobre si su encarcelamiento venía por parte suya y reconocieron que «no resulta cosa alguna contra Gregoria Piedra». Unos días después, los mismos inquisidores Mier, Bergoza y Prado solicitaron que registrara que no estaba ahí por petición suya, pero que sería conveniente investigar si había delito que se pudiera perseguir: la razón, el tiempo de condena y quién le había acusado. A seis años de aquella fecha, en 1802, la santa Inquisición dictó «con atención a que por sus actuaciones no resulta probado crimen alguno de su privativa jurisdicción». En enero de 1805, los inquisidores ordenaron que se asentara en el registro que las denuncias habían sido «despreciadas». En marzo de 1806, los inquisidores Prado y Alfaro aclararon que Gregoria no estaba en el recogimiento por «disposición del Santo Oficio» y suplicaron a Thomas Calderón, gobernador de la Real Sala, esclarecer esta confusión y proporcionar más información sobre el caso a la corte secular y descubrir cuál era el tiempo de condena. Doce años después de aquellos Lunes Santo y Viernes Santo de 1796, en 1808, el presbítero Montejano, capellán del recogimiento de Santa María Magdalena, de nuevo, devolvió «los autos formados por la Real Sala, remitidos por su Gobernador al Tribunal [...] a que Gregoria Piedra está expedita [liberada] por lo correspondiente al Santo Oficio, con atención a que, por sus actuaciones, no resulta probado crimen alguno de su privativa jurisdicción». Durante sus años de clausura, negó enteramente las acusaciones en su contra y notaron que rezaba el rosario y se encomendaba a los santos. Además, tiempo después de la condena, María Vicenta Vargas aclaró que un sacerdote de la iglesia del Sagrario le había instado a acusar a «la Macho» de aquellos delitos.

El caso de Gregoria es un ejemplo del olvido en que cayeron algunas reclusas en los recogimientos. Por haberse prácticamente criado solas, no tenían profesión, conocimientos de usos y costumbres, y siempre estaban en peligro de caer en malas prácticas. Asimismo, su acusadora inicial, María Vicenta, es un ejemplo del abandono en que habían crecido muchas mujeres: analfabetas, sin saber contar, e ignorantes de su propia edad. Además, las cortes seculares y eclesiásticas intercambiaron los autos sobre su caso durante años sin el más mínimo interés en ella. Si la habían mandado a la cárcel en el pasado por vestirse de hombre, tal vez la 
acusación por parte de María Vicenta fue falsa y solo un pretexto para deshacerse de una molestia social.

\section{Juana María Rodríguez «La Paya» \\ (AGN, CÁrceles y Presidios, 15, eXp. 8, FF. 45-90)}

El 16 de marzo de 1794, a medianoche, Juana María Rodríguez «la Paya» murió repentinamente en la casa de recogimiento de Santa María Magdalena en la Puebla de los Ángeles, por «haberle ahogado la sangre». Pese a todas sus súplicas ante las autoridades para pedir clemencia por su mal estado de salud, estas no se enteraron de su muerte hasta cuatro meses después. Las acusaciones en su contra de amancebamiento con dos hombres casados sucesivamente se iniciaron en agosto de 1789, y a pesar de sus explicaciones y justificaciones, mientras los hombres salieron como víctimas, ella se quedó a morir en el recogimiento sin los necesarios cuidados médicos.

Casi tres años después de su condena, «la Paya» llegó ante la corte para rogar por una reducción de su sentencia. En primera persona, duplican su versión de la historia. Ella nació, se entiende, en España, donde se casó muy joven, «en lo más tierno de mi edad», con don José Román, quedando viuda después de dos años y medio, y «permitió mi suerte quedar por su falta, en una lamentable constitución». Arribó a México con su madre y su hermana, ambas tan enfermas que era «indispensable pasar a la corte de México para facilitar su curación». Tenía que sostenerlas sola, una labor tan difícil para la que ella denominó «una infeliz mujer». Con el pretexto de que ella hiciera unas camisas y que se encargara del «cuidado y aseo de su ropa», don Torcuato Montellano, alcalde mayor de Tepeaca, pudo entrar en la casa habitada por ella, su madre y su hermana. Después de un tiempo, él notó su «recato, modestia y recogimiento» y le propuso matrimonio, por lo cual «celebramos solemnemente esponsales, bajo cuyo supuesto, tuve ilícitos comercios con él, esperando siempre el cumplimiento del pacto que celebramos». Reconoció ella que se había rendido a él confiada en la promesa de matrimonio que le había brindado.

Vivieron en este estado por un año, tiempo en el cual, según «la Paya», vivió llorosa y triste por la tardanza del casamiento. En esto, llegó a sus manos una carta de su legítima esposa que vivía en España y, siendo ella una «mujer amante, apasionada y celosa a causa de un desengaño, todo se tornó en disgusto, azares, pleitos y sinsabores», pues, «la Paya» no sabía de su estado conyugal. Por el enojo, arrastrada por su pasión, trató de picarle sus ojos y, finalmente, ella se alejó de él y él regresó a España.

Esta gran tragedia en la vida de Juana habría podido pasar desapercibida para el mundo extramuros familiar, pero tuvo la mala fortuna de toparse con don José 
Pioquinto Hernández, vecino de México. El 12 de agosto de 1789, llegó muy contrito a la corte para alabar a «la gran prudencia de Vuestra Señoría intimarme la separación de la amistad que, como hombre frágil, he mantenido con doña Juana María Rodríguez Calvo». Él insistió que «yo, en puntual obedecimiento de mi ciega obediencia, he procurado solicitar [...] que la susodicha $[\ldots]$ entre [en] un colegio», o sea, un recogimiento. Tuvo tanto aplomo ante los jueces que se atrevió sugerir que sea el «Colegio de Nuestra Señora de Belén [...] u otro que le parezca a Vuestra Señoría». Insistía José Pioquinto en que tal amistad lo alejaba de su matrimonio y, por ello, con el recogimiento de doña Juana se proponía que: «yo libremente, sin este obstáculo, tome a mi esposa la que aguarda para unirse conmigo». Por lo pronto, él se comprometió llevarle al recogimiento:

[...] sus alimentos, y demás necesarios para evitar el que, separada yo de su amistad, tome otras nuevas, y cometa más ofensas a Dios coloreada su malicia con suponer faltarle lo necesario para su manutención a lo que en manera alguna quiere [hacerse frente] sino que lo que pretende es el quedar con libertinaje y sin subordinación ninguna.

Claro, él no cumplió con este compromiso de mantenerla durante su calvario en el recogimiento, sino más bien le creó más problemas.

Durante su testimonio, reivindicando su estado vulnerable ante los encantos de una mujer, Pioquinto la inculpó ante las autoridades. Como si fuera algo insólito, criticó a Juana porque «no tiene ningunas facultadas para sostenerse» y, rencorosamente, espetó: «pues aunque quiere aparentar las tiene en su patria, estoy informado no tener cosa alguna, y que abrigada de este supuesto falso, pretende vivir a su salvo conducto». Por medio de este alegato, se redimió a sí mismo, pero condenó a «la Paya» al recogimiento; y aún más, al olvido al afirmar: «en fuerza de la intimación de Vuestra Señoría y la que me asiste como cristiano para reunirme con doña María Francisca Álvarez, mi legítima mujer, me es preciso practicar las diligencias oportunas a la separación de doña Juana y a la reunión de mi esposa».

El documento estipula que «en aquel acto, y a presencia del mismo señor regente, del capitán de la Real Sala del Crimen, don Vicente de Elizalde, y del comisario Joseph María Martínez, convinieron en reunirse a su matrimonio, obligados de prudentes, cristianas consideraciones, ofreciendo doña Francisca dar para lo sucesivo a un total olvido sus agravios». Tal vez la esposa engañada no fue tan feliz como los comisarios quisieran dar a entender, pues el documento patentiza: «en este concepto expusieron que, aunque la susodicha se regresaba a la casa de su hermana doña Antonia de Álvarez mujer de don Joseph María Quijano, que la acompañaba, a la noche había de ir a ella don Joseph Pioquinto». El supuestamente muy arrepentido y afligido Pioquinto dio a entender a la señoría que la única 
manera de cumplir esto fuera mandar a Juana al recogimiento de Santa María Egipciaca (anterior al arribo de Fernández de Santa Cruz, se denominaba Santa María Magdalena) en la Puebla de los Ángeles a una condena de seis años.

Después de haber tolerado tres años de recogimiento, doña Juana María insistió en que la indultaran porque había prometido:

que hago y cumpliré de no volver a esa ciudad ni sus contornos, de vivir con el mayor recato y honradez, y no dar la menor nota de mi persona. Parece son méritos capaces a que la integridad de Vuestra Excelencia tenga de mí misericordia como lo imploro, pues, aunque la sentencia tiene arbitrio para conmutarla haciendo que salga a una casa particular de las muchas que hay en esta ciudad honra.

Además, reveló que era el mismo pecador, Pioquinto, el que le había acusado por adulterio. «La Paya» subrayó la injusticia en la determinación de recluirla pues, resaltó que «el sujeto de quien se me acusó adulterio se halla reunido a su matrimonio desde el instante que se me remitió a este destino sin enturbio en su matrimonio, en paz y tranquilidad». Por esto, ella también insistió en su absolución. Si ellos están «viviendo una paz tranquila en que me hago juicio que este agravio está perdonado y absuelto, y por consiguiente, lo debe estar el mío, pues contra mí no hay parte que pida».

En enero de 1794, varios médicos advocaron a su favor para que pudiera cuidarse en una casa privada para recibir el alivio y la medicina correctos: dos médicos, de pública aprobación por el real tribunal del proto-medicato del reino del procurador de pobres de la curia, la clasificaron como: «Epiléptica-histérica y se halla su sangre con un humor salso scorbútico de suficiente consideración». En los diccionarios de la época, la epilepsia está definida como: «una enfermedad llamada gotacoral por ser una gota que cae sobre el corazón». Histérico, mientras tanto, designan «mal de madre» una enfermedad que causa una sensación de sofoco y es más común en mujeres.

En el primer caso de «amancebamiento», Juana y Torcuato habían hecho «esponsales» o una promesa de mutuo acuerdo de casarse. Los burócratas españoles frecuentemente sostuvieron nuevas relaciones durante su estancia en la Nueva España y, en muchas ocasiones, cometieron bigamia por la poca esperanza que guardaban de regresar a España con sus esposas legítimas. Juana estaba desesperada porque tenía que mantener a su familia sola, sin las oportunidades adecuadas. La ofendida, en la relación con Torcuato, había sido ella.

Fue Pioquinto el que la acusó con un religioso porque su esposa lo acusó a él ante las autoridades; y él, con el afán de evitar prisión, hizo todo lo posible para manipular la imputación y lograr echarle la culpa a una mujer que, sin saberlo, había vivido amancebada con el español burócrata. Fue por esta razón que él 
informó a las autoridades de su anterior relación con Torcuato, y la acusó de haber abusado de su «fragilidad» como hombre para alejarlo de su esposa. Juana María fue condenada por la Real Sala a seis años de recogimiento, pero murió antes de poder ser enviada a una casa privada para recibir los cuidados médicos adecuados. Pioquinto salió airoso: recuperó a su esposa y demostró su inocencia.

\section{Conclusiones}

En un inicio, los recogimientos tuvieron funciones muy claras en la Nueva España: primero, fomentar la dedicación religiosa por la vía contemplativa; segundo, inculcar buenas costumbres femeninas en las mujeres - como costura, cocina, pintura y tal vez algo de lectura y escritura-; y tercero, encerrar a las mujeres pecadoras/delincuentes para que pudieran arrepentirse de sus vidas erradas y reformarse. En caso de que una mujer se quedara sola - por viudez, divorcio o la lejanía de su pareja - , podría salvaguardar su buena fama por medio de la reclusión.

Poco a poco, las mujeres rebeldes, marginadas o malentendidas, se internaron en estas instituciones durante años y años, con sus expedientes extraviados entre la corte secular y la eclesiástica, sin haber hallado pecado/delito alguno, pero para guardar el orden público, no podían permitir las infracciones a los usos y costumbres de la época. De los tres casos revisados aquí, las mujeres perdieron lo poco que poseían y se encontraron en una maraña burocrática que las ahogó. En el caso de Mariana de la Cruz, ella es culpable de usar bailes y canciones para celebrar alegremente el día de la Santa Cruz, fiesta muy popular en la población mulata y negra de la Nueva España. Tal vez se le aplicó todo el peso de la ley por la promesa del peso de oro de recompensa por cada negro o mulato esclavo o libre capturado por frecuentarse en grupos. Gregoria Piedra «la Macho» fue una joven hombruna que se crió sola y jugaba, hacía travesuras en la calle. Por vestirse como hombre y, tal vez, por ser mulata, sus travesuras no se toleraron. Además, su disidencia genérica habría sido un serio agravio contra la sociedad. Juana María Rodríguez «la Paya» era española, pero esto no le ayudó en nada. Juana era una mujer sola que mantenía a su madre y hermana, las dos enfermas. Cuando tuvo relaciones con Pioquinto, él le acusó de amancebada para poder reunirse con su esposa y así evitar posibles incriminaciones contra su persona. Mientras él salió airoso, ella fue recluida en un recogimiento, donde murió años después, enferma y olvidada. Las ansiedades sociales que crearon mujeres que no guardaron las normas de una vida dócil, obediente al interior de la casa, se perdieron entre los muros del recogimiento. 


\section{BiBLIOGRAFÍA}

Archivo General de la Nación (AGN - México), Cárceles y Presidios, 15, exp. 8, ff. 45 90. Juana María Rodríguez «la Paya».

Archivo General de la Nación (AGN - México), Inq., 1.349, exp. 28, ff. 336-344. Gregoria Piedra «la Macho».

Biblioteca Palafoxiana, ms. [Papeles Varios], ff. [266r-272r], [BP: R475]. Mariana de la Cruz.

CAstillo Hernández, Estela (2014). «Del sermón y sus excesos. Aversión a las mujeres en Nueva España del siglo XVIII». Hispanic Enlightenment, 37.1, pp. 33-62.

HernándeZ-Torres, Yolopattli (2018-2019). «Violencia contra mujeres embarazadas a finales del virreinato mexicano: los ideales ilustrados del Diario de México se confrontan con el hambre, la enfermedad y la muerte». Géneros. Revista de Investigación y Divulgación sobre los Estudios de Género, n. $^{\circ} 24$, época 2 , año 25, pp. 9-28.

Howe, Elizabeth (2008). Education and Women in the Early Modern Hispanic World. London/New York: Routledge.

MAULEÓn, Gustavo (2018). «Acerca de "los bailes y juntas de negros y mulatos" en la ciudad de Puebla de los Ángeles (siglos XVI-XVII)». El pregonero de la ciudad, Nueva Época, 18, pp. 21-25.

MuRIEL, Josefina (1974). Los recogimientos de mujeres. Respuesta a una problemática social novohispana. Ciudad de México: Universidad Nacional Autónoma de México.

Uribe Uraìn, Victor (2016). Fatal Love: Spousal Killers, Law, and Punishment in the Late Colonial Spanish Atlantic. Stanford/California: Stanford University Press.

Recibido: 10/06/2019

Aceptado: 20/08/2019 


\section{ReCogimientos FEMENINOS EN LA Nueva España \\ Y SU PAPEL COMO CÁRCELES PARA MUJERES MARGINADAS}

REsumen: El propósito de este trabajo es examinar el papel de los recogimientos en la Nueva España como cárceles femeninas, en los siglos XVII y XVIII. Por medio de la inspección y el análisis de tres casos de mujeres aprisionadas, dos en el recogimiento de Santa María Magdalena de Puebla y una en Santa María Magdalena de la Ciudad de México, se demuestran la persecución y la condena de mujeres por nimiedades sin distinción entre actos pecaminosos y actos delictuosos. Hubo una confusión entre la justicia secular y la eclesiástica que provocó el olvido de estas personas por años en el encierro.

Palabras ClaVE: recogimientos, Inquisición, mujeres, Nueva España, justicia.

\section{FEMALE RECOGIMIENTOS IN NEW SPAIN AND THEIR ROLE AS JAILS FOR MARGINAL WOMEN}

ABSTRACT: This work's purpose is to examine the function of New Spain recogimientos and their functioning as female prisons in the $17^{\text {th }}$ and $18^{\text {th }}$ centuries. Through an inspection and analysis of three cases of women locked up in two recogimientos, that of Santa Maria Magdalena in the cities of Puebla and Mexico City, the text demonstrates the persecution and sentencing of women for trifles without distinguishing between sinful and unlawful acts. There was a confusion between secular and eclesiastic justice which provoked the disregard of these people for years in jail.

KEYwords: recogimientos, Inquisition, women, New Spain, justice. 